\title{
UTILIZAÇÃO DE ISÓTOPOS AMBIENTAIS NA PESQUISA DE RECURSOS HIIDRICOS SUBTERRÂNEOS NO KARST DA REGIÃO DO JAIIBA, NORTE DE MINAS GERAIS*
}

\author{
ANTONIO PLATA BEDMAR** e ADELBANI BRAZ DA SILVA***
}

\begin{abstract}
The isotopic study of ground surface water from a karstic zone on the north of Minas Gerais State (Januária - Manga) provided some clues to indentify aquifer characters. That local rainfall have originated all the ground water was showed by the analysis of deuterium and oxigen-18. The isotopic concentration was found irregularly distributed, which is an indicative of site recharge, flow, and ill-dispersion of waters. The tritium ratified observations obtained by other isotopes and have provided ground to conclude that ground water was recently accumulated. However, none correlation was determined among the isotopes and other environment data, except for a decreasing in tritium concentration according to the depth of the fractured zones.
\end{abstract}

INTRODUÇÃO Os isótopos ambientais que estão envolvidos no ciclo hidrológico vêm sendo utilizados nos últimos anos como traçadores naturais nos estudos dos recursos hídricos subterrâneos. Os principais isótopos utilizados são o deutério, oxigênio 18 e o trítio. Os dois primeiros são estáveis e encontrados em todas as águas em proporção que varia de acordo com suas origens. $O$ trítio é radiativo e produzido na atmosfera pela radiação cósmica ou, mais recentemente, pelas explosões termonucleares (bomba de hidrogênio). Sua concentração nas águas varia com a idade das mesmas ou por contaminação das explosões termonucleares.

$\mathrm{Na}$ área do projeto "Pesquisa e Avaliação de Recursos Hídricos Subterrâneos em Karst por Sensores Remotos" (Silva, 1978), Fig. 1, foi realizada uma amostragem de águas subterrâneas em poços tubulares e águas superficiais em rios e lagoas para análise de isótopos ambientais com o objetivo de definir as principais características do aquífero cárstico. Os resultados das análises de deutério, oxigênio 18 e trítio também foram comparados com outros parâmetros, tais como salinidade, tipo de fluxo nos poços e profundidade das fendas.

ISÓTOPOS ESTÁVEIS DA ÁGUA Para a interpretação das análises isotópicas das àguas subterrâneas é necessário o conhecimento da composição isotópica das precipitações locais. No entanto, devido às numerosas variáveis que determinam esta última composição e ao fato de as águas subterrâneas serem representativas das precipitaçðes médias no período útil de recarga, teria que se dispor de um número elevado de dados referidos a muitos anos e as composiçð̃es isotópicas médias mensais ponderadas, isto é, levando-se em conta a precipitação média.

Devido à falta total de dados isotópicos para as precipitaçðes locais na área do projeto, foram utilizados os dados existentes nas estações do Rio de Janeiro e

Brasília (aeroporto), incluídos na rede mundial de pontos controlados pela Agência Internacional de Energia Atômica (AIEA) e pela Organização Meteorológica Mundial (OMM) para análise isotópicas das precipitaçðes. As condiçðes meteorológicas da área de estudo são similares às existentes na zona de Brasília e o grau de continentalidade é semelhante. Uma comparação das composiçð̄es isotópicas das precipitaçð̃es nas duas estaçð̃es indicadas pode dar uma idéia da ordem de grandeza das variações que se podem esperar da área do estudo e Brasilia.

Com os dados das composiç̃es isotópicas médias mensais publicados (valores ponderados), foram calculadas as correspondentes às precipitaçôes médias anuais ponderadas por meio da seguinte expressão:

$$
\delta_{a}=\sum \frac{\mathrm{Pm}}{\mathrm{Pa}} \cdot \delta_{m}
$$

sendo $\delta_{a}$ e $\delta_{m}$ os desvios médios anual e mensal, respectivamente, e $\mathrm{Pa}$ e $\mathrm{Pm}$ as precipitações anual e mensal, respectivamente.

Como o período útil para a recarga do aquífero compreende os meses de outubro a abril, foram também calculados os valores de $\delta$ referentes a este período, isto é, considerando-se os valores de $\delta_{m}, \mathrm{~Pa}$ e Pm para tal período. Os resultados obtidos encontram-se na Fig. 2. Os pontos correspondem ao período de 1962 a 1975 , embora faltem alguns anos já que os dados mensais publicados são incompletos. Pode-se observar que a maior parte dos pontos se ajusta à reta de equação $\delta_{D}=8 \delta_{18}+$ 10 , como era de esperar. Os valores médios para o período de 1962 a 1975 são os seguintes:

Rio de Janeiro

Ano completo (\%)

Período outubro-abril $(\%)$

$$
\begin{aligned}
& \delta_{D}=-25,5 ; \delta_{18}=-4,5 \\
& \delta_{D}=-28,6 ; \delta_{18}=-4,8
\end{aligned}
$$

\footnotetext{
* Trabalho realizado com auxilio do Conselho Nacional de Desenvolvimento Cientifico e Tecnológico (CNPq)

** Ministério de Obras Públicas, Espanha

*** Fundação Centro Tecnológico de Minas Gerais (CETEC)
} 


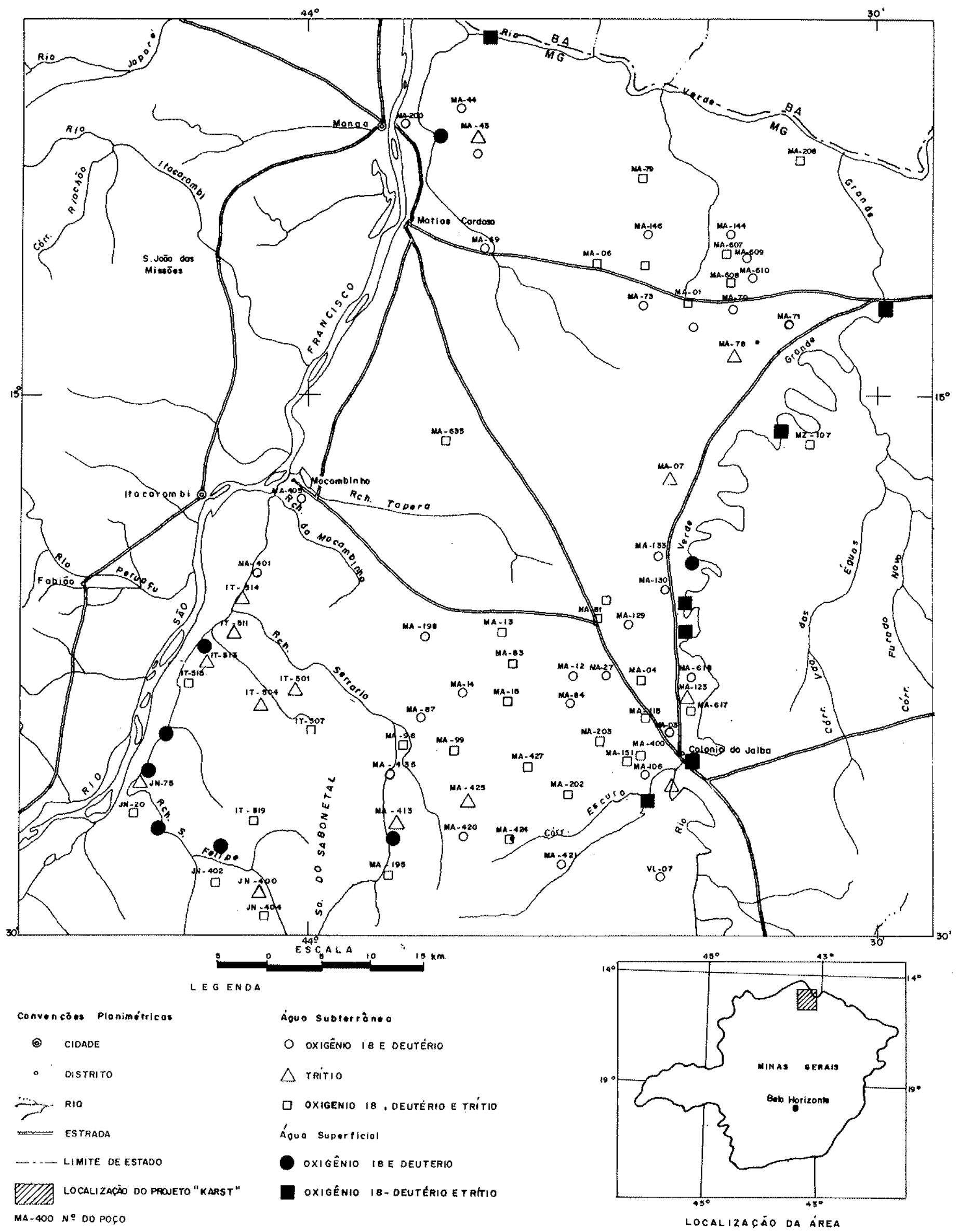

Figura 1 - Localização dos pontos amostrados 


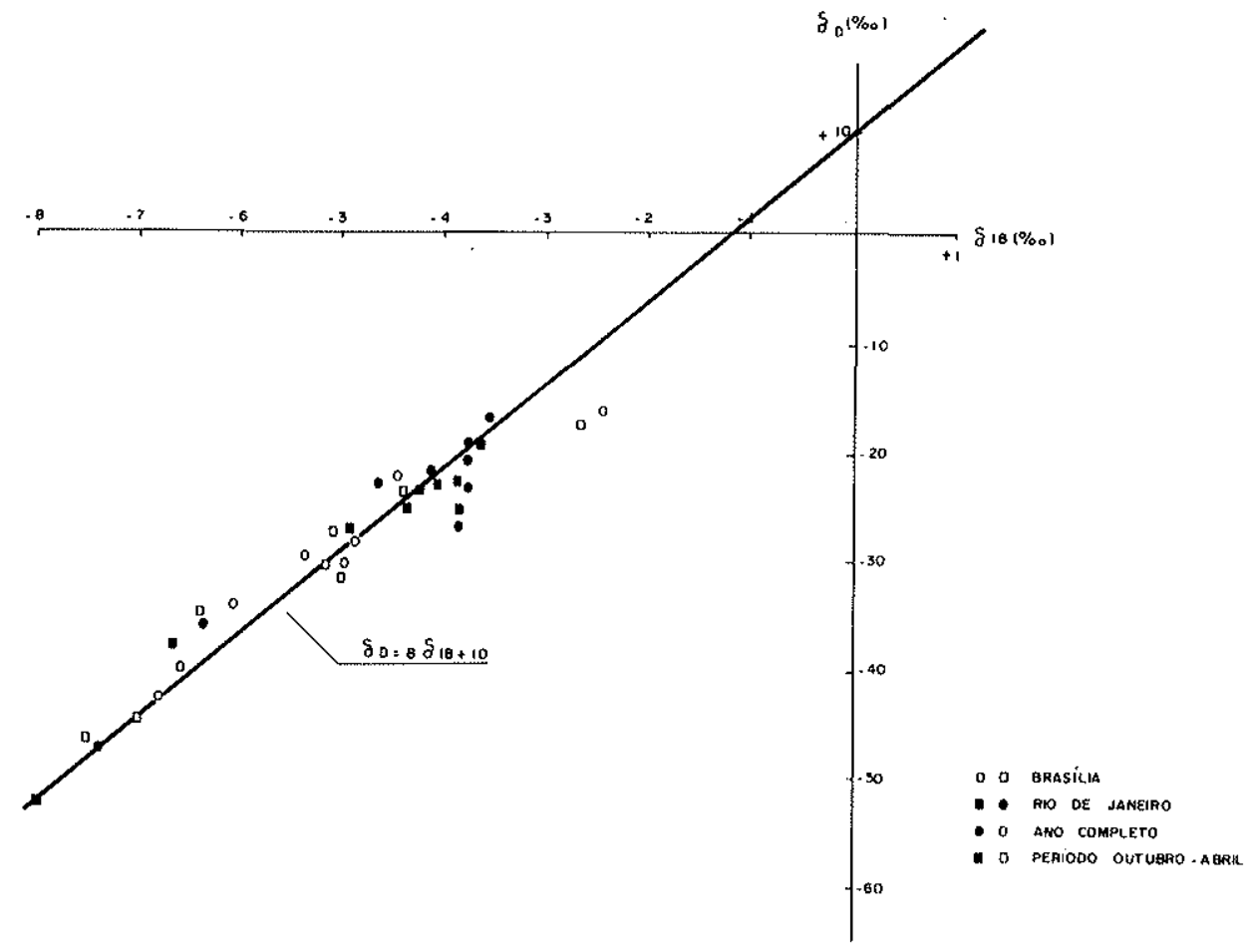

Figura 2 - Composição isotópica média das precipitaçð̃es de Brasília e Rio de Janeiro

$$
\begin{array}{ll}
\text { Brastlia } & \delta_{D}=-30,7 ; \delta_{18}=-5,1 \\
\text { Ano completo }(\%) & \delta_{D}=-32,2 ; \delta_{18}=-5,3
\end{array}
$$

Observa-se que as precipitaçðes de Brasília são isotopicamente mais leves (mais negativos) que as do Rio de Janeiro, o que era de esperar devido ao maior grau de continentalidade da primeira estação. As diferenças de composição média para o ano completo e para o período outubro-abril justificam-se pela maior pluviosidade. Pode-se supor que as precipitaçoes da área de estudo devem ter uma composição isotópica média compreendida entre os valores para o Rio de Janeiro e Brasilia, se bem que a área se encontra mais próxima desta última estaç̃̃o.

Com os dados publicados pelos organismos AIEA e OMM para Brasília, foram elaboradas as curvas da Fig. 3, que representam a distribuição da precipitação média ao longo do ano e da composição isotópica $\left(\delta_{D}\right)$ para esta mesma precipitação. $\mathrm{O}$ período de tempo incluído compreende de 1966 a 1975 , isto é, dez anos. Os valores médios de $\delta_{p}$ foram calculados pela equação $\delta_{D}=8 \delta_{18}$ + 10 a partir das médias mensais dos valores de $\delta_{18}$. Dessa forma é possível melhorar a precisão estatística. Os valores correspondentes ao mês de janeiro afastam-se muito das curvas devido à influência negativa de dois dados, muito diferentes dos outros.

Observa-se que a maior parte das precipitaçð̃es ocorre entre outubro e abril. Por outro lado, observa-se um bom paralelismo entre a curva da precipitação média e a curva correspondente ao valor de $\delta_{D}$. A medida que aumenta a pluviosidade, as precipitaçðes são isotopicamente mais leves. Em zonas de clima temperado, este

fenômeno é explicado pelas diferenças de temperatura ambiente entre inverno (época de maior pluviosidade) e verão. Mas, em Brasília, como as diferenças de temperatura são pequenas, o fenômeno tem que ser explicado como consequiência da evaporação parcial das gotas de chuva durante sua queda da a nuvem ao solo. Esta evaporação parcial leva um fracionamento isotópico e a gota que chega na superfície do solo é tanto mais rica em isótopos estáveis quanto maior for a evaporação sofrida. A evaporação aumenta quando diminui a intensidade da chuva. Por isso as precipitaçðes dos meses mais secos têm valores de $\delta_{D}$ mais positivos. Para os meses de junho, julho e agosto não se têm dados porque a precipitação registrada foi quase sempre zero. Para setembro, dispoe-se de sete dados, seis dos quais correspondem a valores positivos de $\delta_{D}$.

Com as curvas da Fig. 3 é possível calcular o valor médio provável de $\delta_{D}$ nas águas subterrâneas provenientes de infiltração de precipitaçós em diferentes épocas do ano. Para se obter valores ponderados é preciso levar em conta as diferentes pluviosidades médias de cada mês, utilizando um somatório semelhante ao indicado em (1). Os cálculos realizados dão os seguintes resultados:

\section{Período de recarga}

Dezembro-janeiro

Novembro-fevereiro

Outubro-março

Outubro-abril

Setembro-abril
Valor de $\delta_{D}(\%)$

$$
\begin{array}{r}
-42,2 \\
-38,5 \\
-34,7 \\
-32,8 \\
-32,5
\end{array}
$$




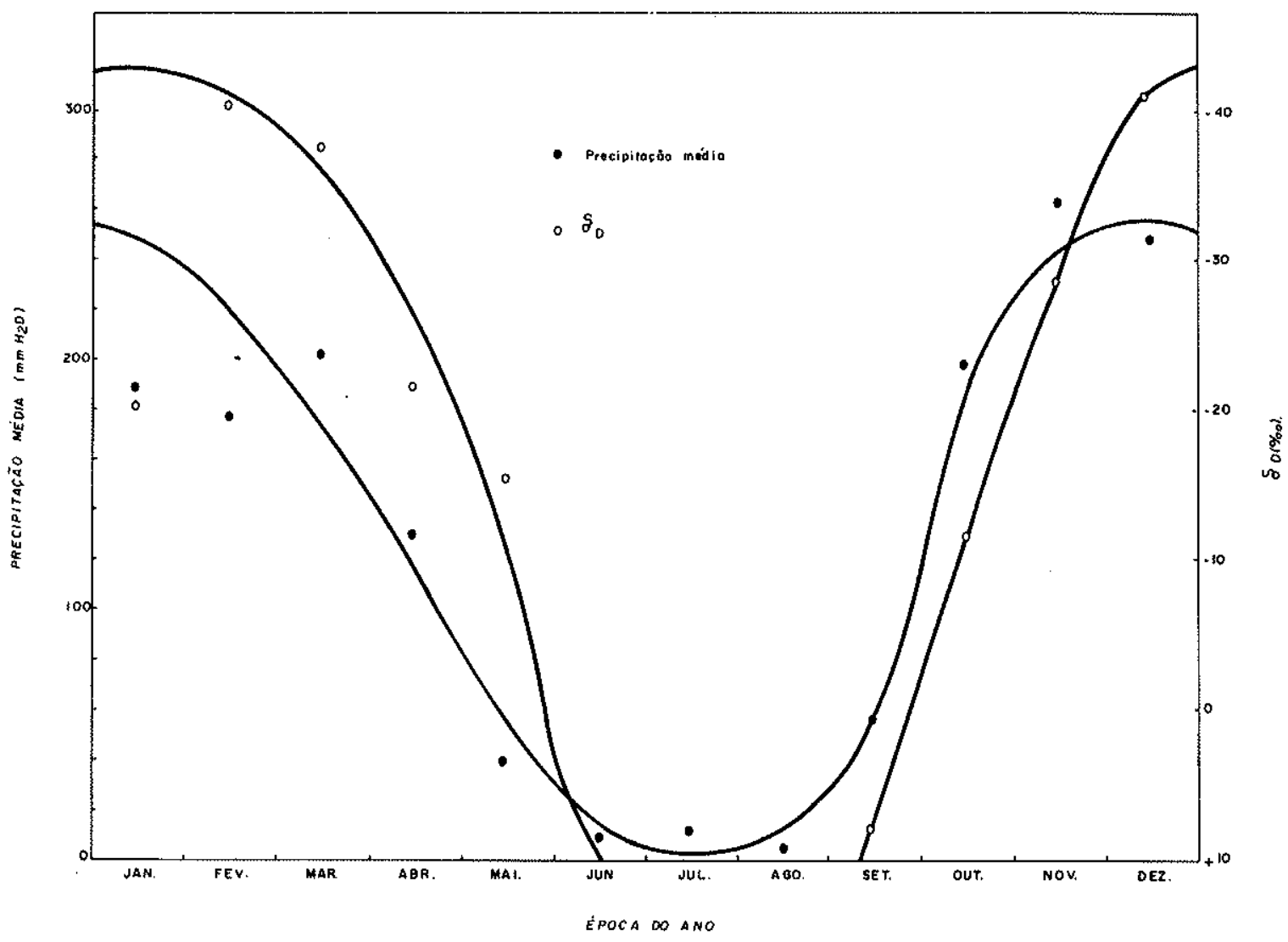

Figura 3 - Valores médios das precipitaçð̃es e do desvio $\delta_{D}$ para as precipitaç̃̃es em Brasília (aeroporto), durante o periodo 1966-1975

O valor para o período outubro-abril é muito parecido ao calculado com os dados da Fig. 2 ( $-32,3 \%$ ).

No aquífero cárstico estudado era de esperar valores de $\delta_{D}$ dessa mesma ordem de grandeza.

RESULTADOS OBTIDOS Os resultados obtidos nas análises isotópicas das amostras de águas coletadas são indicados na Tab. 1. Todas as análises foram efetuadas pelo Centro de Energia Nuclear na Agricultura de Piracicaba (São Paulo). Os erros prováveis das análises são de $\pm 2 \%$ para $\delta_{D}$ e $0,2 \%$ para $\delta_{18}$.

Em linhas gerais, os resultados concordam satisfatoriamente com os valores previstos no item anterior. Dos 65 dados existentes, 46 encontram-se no intervalo compreendido entre $-32 \%$ e $-42 \%$ para $\delta_{D}$. Os valores médios para os 65 poços são $\delta_{D}=-38,7 \%$ e $\delta_{18}=$ $-5,84 \%$ que, segundo os dados do item anterior, corresponderiam a um período médio de recarga compreendido entre novembro e fevereiro. No entanto, esse fato não pode ser considerado como resultado definitivo porque as composições isotópicas das precipitaçðes locais podem ser algo diferentes das de Brasília e também porque, em alguns casos, a água coletada no poço pode não ser representativa das precipitações médias da zona.
Além dessas 65 amostras coletadas em poços, foram efetuadas análises isotópicas de outras onze amostras de águas superficiais que incluíam diversas lagoas e os rios Verde Grande e Serraria. Os resultados obtidos mostram-se na Tab. 2. Trata-se de águas que experimentaram evaporação, em maior o menor extensão, e por essa razão os desvios de deutério e oxigênio 18 são mais positivos que os das águas subterrâneas. A interpretação desses resultados, assim como dos correspondentes aos poços, é feita nos itens seguintes.

\section{INTERPRETAÇÃO DOS RESULTADOS}

Relação entre deutério e oxigênio 18 Na Fig. 4, encontra-se o gráfico em que são relacionados os valores de $\delta_{D}$ e $\delta_{18}$. Neste gráfico observa-se que a maior parte dos pontos de águas subterrâneas se ajusta satisfatoriamente à reta de equação $\delta_{D}=8 \delta_{18}+10$, que, como se sabe, corresponde às precipitaçðes da maioria das regiōes do globo. Por outro lado, as águas superficiais ajustam-se melhor a uma reta com declive de 5 , como consequêencia da evaporação. A dispersão dos pontos pode ser explicada uma vez que, antes do processo de evaporação, a composição isotópica original das águas 
Tabela 1 - Resultados das análises de ${ }^{18} O$ e $D$ da água dos poços

\begin{tabular}{|c|c|c|c|c|c|}
\hline Poço & $\delta_{D}(\%)$ & $\delta_{18}(\% \circ)$ & Poço & $\delta_{\mathrm{D}}(\% \mathrm{o})$ & $\delta_{18}(\% \circ)$ \\
\hline MA- 01 & -39 & $-5,6$ & MA-200 & -49 & $-7,1$ \\
\hline MA- 03 & -38 & $-5,6$ & MA-203 & -38 & $-5,7$ \\
\hline MA- 06 & -49 & $-7,1$ & MA-400 & -38 & $-5,6$ \\
\hline MA- 12 & -36 & $-5,7$ & MA-402 & -34 & $-4,9$ \\
\hline MA- 13 & -37 & $-5,8$ & MA-405 & -45 & $-7,2$ \\
\hline MA- 14 & -41 & $-6,4$ & MA-417 & -38 & $-5,6$ \\
\hline MA- 15 & -38 & $-5,6$ & MA-420 & -37 & $-5,8$ \\
\hline MA- 43 & -44 & $-5,6$ & MA-422 & -40 & $-6,0$ \\
\hline MA- 44 & -40 & $-5,8$ & MA-427 & -36 & $-5,3$ \\
\hline MA- 69 & -38 & $-6,1$ & MA-435 & -38 & $-5,0$ \\
\hline MA- 71 & -38 & $-5,0$ & MA-604 & -32 & $-5,0$ \\
\hline MA- 73 & -36 & $-6,3$ & MA-607 & -51 & $-7,2$ \\
\hline MA- 78 & -41 & $-6,2$ & MA-608 & -35 & $-5,0$ \\
\hline MA- 79 & -36 & $-5,5$ & MA-610 & -35 & $-5,0$ \\
\hline MA- 81 & -41 & $-6,1$ & MA-612 & -42 & $-6,6$ \\
\hline MA- 83 & -41 & $-6,5$ & MA-613 & -42 & $-5,9$ \\
\hline MA- 84 & -36 & $-5,4$ & MA-615 & -39 & $-6,1$ \\
\hline MA- 87 & -29 & $-6,1$ & MA-617 & -47 & $-6,5$ \\
\hline MA- 98 & -31 & $-3,8$ & MA-618 & -44 & $-6,4$ \\
\hline MA- 99 & -35 & $-5,4$ & MA-623 & -41 & $-6,0$ \\
\hline MA-106 & -39 & $-5,6$ & MA- 625 & -34 & $-4,4$ \\
\hline MA-127 & -39 & $-5,9$ & MA-630 & -37 & $-5,2$ \\
\hline MA-130 & -52 & $-7,1$ & MZ-107 & -45 & $-6,4$ \\
\hline MA-131 & -41 & $-6,1$ & $\mathrm{JN}-21$ & -40 & $-5,4$ \\
\hline MA-133 & -49 & $-6,7$ & $\mathrm{JN}-401$ & -35 & $-5,3$ \\
\hline MA-134 & -45 & $-6,6$ & JN-404 & -39 & $-5,6$ \\
\hline MA-145 & -37 & $-5,9$ & IT-501 & -45 & $-6,9$ \\
\hline $\mathrm{MA}-146$ & -30 & $-5,2$ & IT -512 & -48 & $-6,9$ \\
\hline$\underline{\text { MA-148 }}$ & -34 & $-5,0$ & IT-520 & -35 & $-5,9$ \\
\hline MA-151 & -31 & $-5,9$ & VL-007 & -41 & $-6,0$ \\
\hline MA-195 & -23 & $-5,5$ & MA-202 & -38 & $-5,6$ \\
\hline MA-198 & -30 & $-5,2$ & & & \\
\hline
\end{tabular}

não é a mesma. Esse declive de 5 é igual ao obtido para a evaporação no nordeste brasileiro.

Uma conclusão que se pode tirar desses resultados é que as águas subterrâneas do sistema cárstico procedem de precipitações locais infiltradas diretamente no aquífero, isto é, com evaporação prévia pequena antes da infiltração. Portanto o tempo médio de permanência das àguas em superfície é pequeno. Se isso não ocorresse, os pontos das águas subterrâneas ficariam à direita $\mathrm{e}$ bem afastados da reta da equação $\delta_{D}=8 \delta_{18}+10$. Isso acontece só em casos isolados, como são os poços MA-98, MA-625 e MA-43. Além do erro próprio de análise isotópica, a dispersão dos pontos justifica-se, em parte, porque um pouco de evaporação sempre ocorre antes. da infiltração da água e, também, porque as amostras coletadas são uma mistura de precipitações diferentes infiltradas durante um número elevado de anos. Tudo parece indicar que a permeabilidade das ca- 
Tabela 2 - Resultados das análises isotópicas de amostras de águas superficiais

\begin{tabular}{c|c|c|c}
\hline Referência & Localização & $\delta_{D}(\%)$ & $\delta_{18}\left(\%_{0}\right)$ \\
\hline M-1 & Rio Verde & -35 & $-4,7$ \\
\hline M-2 & Rio Verde & -32 & $-4,7$ \\
\hline M-3 & Rio Verde & -33 & $-4,7$ \\
\hline M-4 & Rio Verde & -27 & $-3,4$ \\
\hline M-5 & Lagoa & -22 & $-0,3$ \\
\hline M-6 & Lagoa & -34 & $-3,0$ \\
\hline M-7 & Lagoa & -36 & $-3,0$ \\
\hline M-8 & Lagoa & -11 & $-1,5$ \\
\hline M-9 & Lagoa & +4 & $+3,0$ \\
\hline M-10 & Lagoa & -8 & $-0,6$ \\
\hline M-11 & Rio Serraria & -32 & $-4,9$ \\
\hline
\end{tabular}

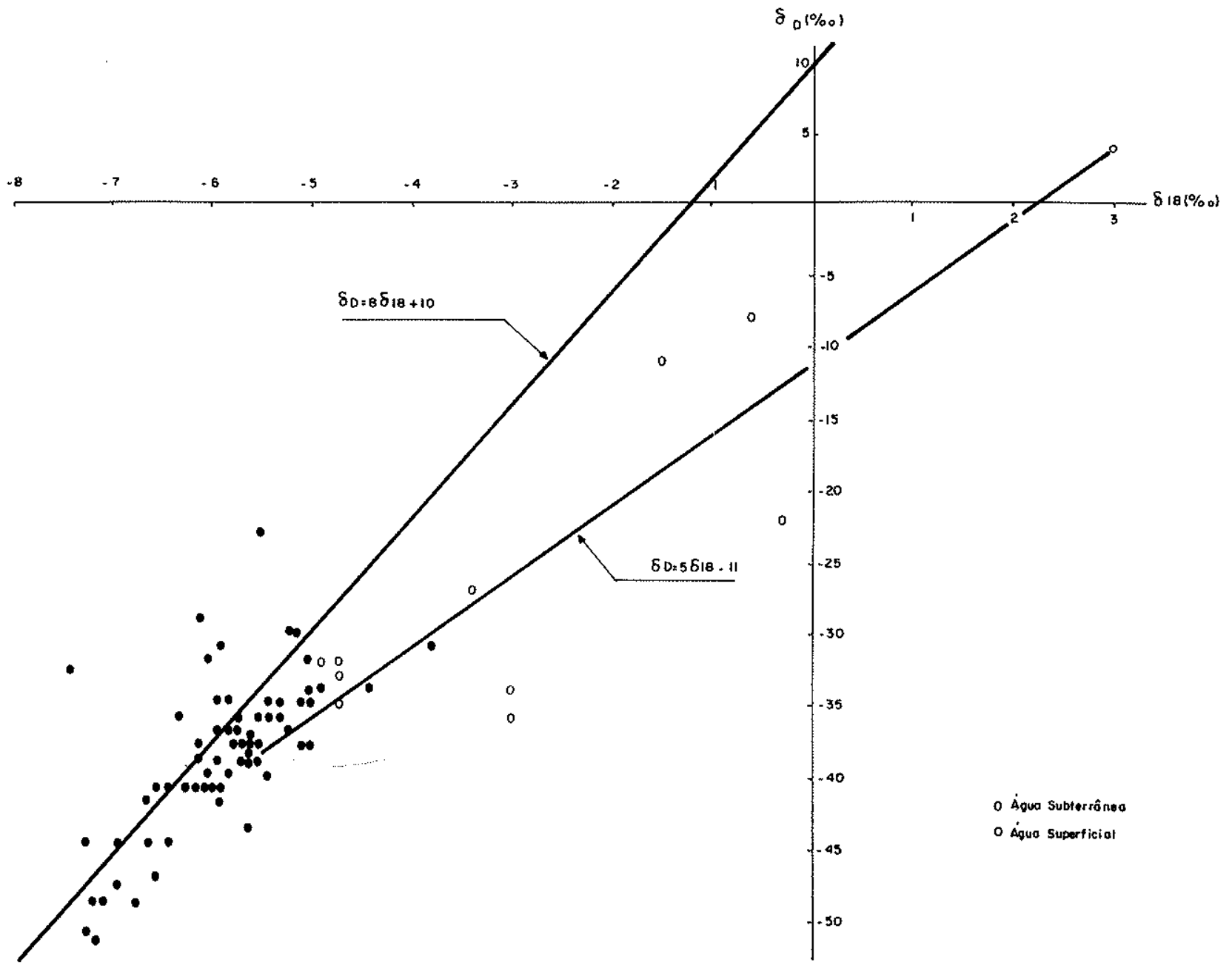

Figura 4 - Diagrama $\delta_{D}$ versus $\delta_{18}$ para as amostras coletadas de águas subterrâneas e superficiais 
madas superficiais do solo é relativamente elevada e a água não realiza longos percursos pela superfície antes de sua infiltração.

Quando a precipitação é pouco intensa, a água evapora e não chega ao nível piezométrico mas, se é intensa, a infiltração ocorre rapidamente. Os termos médios devem ser escassos.

Distribuição das concentrações isotópicas Em linhas gerais, observa-se uma distribuição de concentraçð̃es isotópicas completamente irregular na área, a qual parece indicar que cada poço é representativo de um pequeno entorno do aquífero com condiçðes de recarga características e diferentes das correspondentes a outras áreas próximas. Em outras palavras, a mistura da água no aquífero se produz com muita dificuldade, o que por outro lado é normal em aquíferos de rochas fendilhadas.

Dentro da zona estudada, existem duas áreas onde a densidade de poços perfurados é maior que no resto. Uma dessas áreas encontra-se situada no triângulo formado pela Colônia da Jaíba, povoado de Serraria e serra do Sabonetal e a outra na região de Lagedinho e Lagedão. Observa-se que as águas dessas duas áreas têm maiores concentraçðes de isótopos pesados (valores menos negativos). Os valores médios para tais áreas são: $\delta_{D}$ $=-36,3 \%$ e $\delta_{18}=-5,58 \%$ e para as restantes são $\delta_{D}$ $=-41,1 \%$ e $\delta_{D}=-6,04 \%$. É difícil explicar essa diferença de composição isotópica média baseada em razões climatológicas ou nas características de fendilhamento do aquífero. Uma possível explicação dessa diferença pode-se encontrar no regime de exploração do aquífero. Nas duas áreas de maior densidade de poços, os níveis piezométricos estão mais baixos em conseqüência da extração de água. Nessas condições, a recarga do aquífero é mais favorecida nessas áreas que nas outras onde não existe extração. Por outro lado, a composição isotópica média da água no aquífero depende da amplitude do período de recarga. Quando esse período aumenta, as águas têm um conteúdo maior de isótopos pesados. Portanto pode-se pensar que, como consequiência da extração de água nos poços, o período de recarga é maior e por isso os valores de $\delta$ são menos negativos. Como foi visto anteriormente, a composição isotópica média das duas áreas com maior exploração do aquífero corresponderia a um período de recarga aproximado de novembro a março e para o resto da área seria de dezembro a fevereiro. Logicamente, essas consideraçōes têm só um valor qualitativo no que se refere à explicação do fenômeno observado.

Além dessa informação, as concentraçðes de isótom pos' estáveis, juntas com a fornecida pelo trítio, a qual será referida adiante, podem servir para identificar a relação existente entre poços próximos. Por exemplo, os poços MA-151 e MA-400 têm uma recarga diferente, apesar de se encontrarem muito próximos um do outro. Os poços MA-99, MA-427 e possivelmente MA-84 têm a mesma água etc. Por outro lado, era de esperar que alguns dos poços próximos às serras Azul e Sabonetal tivessem águas muito leves isotopicamente como conseqüência da recarga em cotas elevadas (efeito de altitude). Isso não se observa de forma clara o que re- força a afirmação de que as águas coletadas nos poços correspondem à recarga local. Os longos deslocamentos da água devem realizar-se em canais de dissolução bem localizados.

Relação com outros parâmetros Com os dados disponiveis, tentou-se estabelecer uma correlação entre a concentração isotópica da água e outros parâmetros, tais como salinidade, tipo de fluxo encontrado no poço e concentração de trítio. Só esta última deu um resultado positivo, como se verá adiante.

A não-existência de correlação entre a composição isotópica e a salinidade indica que o fenômeno de evaporação em superfície não contribui de forma sensível na salinização da água. Isso concorda com o exposto anteriormente, quando ficou demonstrada a pouca importância da evaporação prévia. A maior parte da salinização da água acontece após sua infiltração.

Composição isotópica do rio Verde Grande As amostras de n. 1 até 4 da Tab. 2 correspondem a águas coletadas no rio Verde Grande nos pontos indicados no mapa da Fig. 1. As três primeiras amostras têm a mesma composição isotópica com os valores médios $\delta_{D}=$ $-33,3 \%$ e $\delta_{18}=-4,7 \%$. Esses valores correspondem a concentrações de isótopos pesados um pouco maiores que as existentes no aquífero. A diferença pode-se justificar pela evaporação da água durante seu percurso ao longo do rio.

Por outró lado, deve-se ressaltar que a concentração de isótopos estáveis é constante ao longo do trecho compreendido entre colônia da Jaíba e Gado Bravo. Devido à ausência de novos aportes de água, esta seria cada vez mais pesada isotopicamente devido à evaporação. De acordo com as características do rio, com o comprimento do trecho indicado (aproximadamente $120 \mathrm{~km}$ ) e com a taxa de evaporação local, poder-se-ia esperar um aumento de concentração de deutério compreendido entre $4 \%$ e $8 \%$. A única explicação para a não existência desse incremento é que, no trecho indicado, se produz a descarga no rio de um volume de água do aquífero com valores de $\delta$ mais negativos, o que compensa o mencionado incremento. Se for aceito um valor médio de $-6 \%$, para este incremento e um valor de $-41,1 \%$ para o desvio $\delta_{D}$ da água do aquífero, obtém-se uma vazão de descarga do aquífero no rio igual a $77 \%$ da vazão deste em colônia da Jaíba.

No trecho compreendido entre Gado Bravo e a desembocadura do rio, as concentraçóes isotópicas aumentam até $\delta_{D}=27 \%$ e $\delta_{18}=-3,4 \%$. Este resultado poderia indicar que a descarga do aquífero no rio é pequena ou inexistente porque o aumento de concentração pode ser justificado pela evaporação. No entanto não é possível obter conclusão alguma sobre este trecho já que, no mesmo, o rio Verde Grande recebe o rio Verde Pequeno e não se dispóem de dados sobre a vazão e composição isotópica deste último. Possivelmente, o rio Verde Pequeno aporta água com elevada concentração de isótopos estáveis, a qual, junto com a evaporação, justifica o aumento de concentração, mesmo existindo uma certa descarga do aquífero. Como se verá adiante. 
o trítio fornece mais informações sobre a descarga de água do aquífero ao rio.

TRÍTIO $\mathrm{O}$ trítio $(\mathrm{T})$ é um isótopo radiativo de hidrogênio com número de massa $3\left(3_{\mathrm{H}}\right)$. Desintegra-se por emissão de partículas beta, segundo uma vida média de 12,3 anos. de:

A presença de trítio nas precipitaçð̋es é decorrente

a) Emissão direta do Sol.

b) Produção na alta atmosfera por meio de reaçðes nucleares de radiaçóes de elevada energia (radiação cósmica) com os gases existentes.

- c) Explosões termonucleares (bomba de hidrogênio) efetivadas na atmosfera a partir de 1952.

As duas primeiras fontes de produção de trítio (trítio cosmogênico) têm atuado permanentemente produzin. do concentrações nas precipitações compreendidas entre duas e dez unidades de trítio (U.T.) A unidade de trítio corresponde a uma relação em número de átomos presentes, $\mathrm{T} / \mathrm{H}=10^{-18}$. Assim 1 U.T. equivale a $3,2 \times$ $10^{-3}$ microcurie por metro cúbico de água.

Por outro lado, devido à grande quantidade de trítio liberado na atmosfera pelas explosðes termonucleares, a concentração desse isótopo nas precipitaçôes chegou a atingir valores até 1000 vezes maiores que os existentes anteriormente aos ensaios nucleares. $O$ trítio liberado na atmosfera dá lugar à formação de moléculas de água do tipo THO, sendo, então, incorporado ao ciclo hidrológico.

Quando uma massa de água fica isolada no subsolo, após a infiltração, sua concentração de trítio diminui de acordo com a vida média desse material radiativo. Devido à desintegração natural do trítio, as concentrações de águas infiltradas anteriormente a 1952 não são detectáveis na atualidade. Portanto o fato de se encontrar trítio numa amostra de água subterrânea indica a existência de água procedente de precipitações posteriores a este ano.

CONCENTRAÇÃO DE TRÍTIO NAS PRECIPITAÇÕES DA ÂREA EM ESTUDO Não existem dados das concentrações de trítio nas precipitaçōes da área do estudo. Contudo essas concentraçðes podem ser avaliadas com suficiente aproximação a partir dos dados conhecidos de áreas próximas e da informação que se tem sobre a distribuição de trítio na escala mundial.

As estações mais próximas incluídas na rede controlada pelos organismos AIEA e OMM encontram-se em Brasília (aeroporto) e Rio de Janeiro, as mesmas que controlam os isótopos estáveis da água. Os dados disponíveis correspondem às concentrações médias ponderadas mensais para o período $1965-1975$. Com tais valores foram calculadas as concentraçðes médias anuais e as concentraçốes médias do possível período útil de recarga (de outubro até abril). Os resultados encontram-se na Tab. 3 para o período indicado. Observa-se que não existe uma diferença sistemática entre as concentraçőes para o ano inteiro e para o período outubro-abril. Comparando as concentrações de Brasília e do Rio de Janeiro, observa-se que as desta última estação são aproxi- madamente $20 \%$ mais baixas. Isso era de esperar devido à diferença no grau de continentalidade das duas estações.

Por outro lado, sabe-se que as concentrações relativas de trítio nas precipitaçōes dos diferentes pontos do globo conservam valores razoavelmente constantes. Isso se deve à distribuição das concentraç̃es médias anuais determinada basicamente pela distribuição no tempo das próprias explosões termonucleares, que é a mesma para todo o globo. Por isso é possível estimar as concentrações médias anuais para os períodos sem dados. Geralmente, segue-se para essa estimativa o modelo de distribuição obtido para Ottawa (Canadá), porque é, possivelmente, conhecido com maior exatidão. Por esse procedimento foram determinadas as concentraçōes médias anuais para o período de 1953-1964, do qual não existem dados. Os resultados são os indicados na Tab. 3. Os valores para os anos de 1976 e 1977 foram determinados por extrapolação gráfica dos correspondentes aos anos anteriores. Sabe-se, pela distribuição mundial das concentraçoes de trítio, que existe um efeito de continentalidade segundo o qual as concentrações médias aumentam quando se passa do litoral para o interior dos continentes. Esse ef eito não está bem estabelecido quantitativamente na América do Sul. Por essa razão as concentrações médias de trítio para a área de estudo no período outubro-abril foram calculadas, de forma aproximada, pela expressão $C=\left(3 C_{B}+C_{R}\right) / 4$, sendo $C_{B} e$ $C_{R}$ as concentrações correspondentes em Brasília e Rio de Janeiro, respectivamente. Os valores encontram-se na última coluna da Tab. 3 e serão utilizados para determinar o tempo de renovação da água no aquífero.

RESULTADOS OBTIDOS As concentrações de trítio obtidas nas amostras de águas coletadas nos poços em alguns pontos de fluxos superficiais (rio Verde Grande) figuram na Tab. 4. Todas as análises foram efetuadas pelo Centro de Desenvolvimento da Tecnologia Nuclear (CDTN-Nuclebrás) de Belo Horizonte (MG). Os erros indicados correspondem ao desvio 2 , sendo $\delta$ o desvio típico ou standard.

O valor de trítio obtido para o poço MA-83 (83 U.T.) parece muito elevado sendo difícil justificá-lo pelo mecanismo de recarga do aquífero. Possivelmente tenha sido cometido erro na análise. Também está elevada a concentração de trítio obtida para o poço MA-420 $(20,8$ U.T), mas neste caso não parece claro que houve algum erro na análise. Nos casos das amostras dos poços IT-501 e IT-512, foram fornecidos para cada poço dois resultados muito diferentes, os quais são indicados na Tab. 4. Para a interpretação foram utilizados só os dois valores mais elevados, que parecem estar mais de acordo com o conjunto de dados.

Em linhas gerais, os resultados indicam que as águas subterrâneas da área são do período termonuclear, isto é, são águas provenientes da infiltração de precipitações posteriores ao ano de 1952. Este fato confirma que o sistema tem uma resposta rápida às precipitações e que o tempo de renovação da água não pode ser muito grande. 
Tabela 3 - Concentrações de trítio nas precipitações de Brasília, Rio de Janeiro e área do estudo

\begin{tabular}{l|c|c|c|c|c}
\hline \multirow{2}{*}{ ANO } & \multicolumn{5}{|c}{ CONCENTRAÇÃO DE TRÍTIO (U.T.) } \\
\cline { 2 - 6 } & \multicolumn{2}{|c|}{ BRASÍLIA } & \multicolumn{2}{c}{ RIO DE JANEIRO } & ÁREA DO ESTUDO \\
\cline { 2 - 6 } & $\begin{array}{c}\text { Média } \\
\text { anual }\end{array}$ & $\begin{array}{c}\text { Periodo } \\
\text { outubro-abril }\end{array}$ & $\begin{array}{c}\text { Média } \\
\text { anual }\end{array}$ & $\begin{array}{c}\text { Período } \\
\text { outubro-abril }\end{array}$ & $\begin{array}{c}\text { Período } \\
\text { outubro-abril }\end{array}$ \\
\hline 1955 & 3,7 & & 3,0 & & 3,5 \\
\hline 1956 & 12,3 & & 10,0 & & 11,7 \\
\hline 1957 & 8,1 & & 6,6 & & 7,7 \\
\hline 1958 & 40,3 & & 32,7 & & 38,4 \\
\hline 1959 & 47,8 & & 38,8 & & 45,5 \\
\hline 1960 & 12,5 & & 10,1 & & 11,9 \\
\hline 1961 & 13,1 & & 10,7 & & 12,5 \\
\hline 1962 & 76,7 & & 62,3 & & 73,1 \\
\hline 1963 & 252,2 & & 204,6 & & 144,7 \\
\hline 1964 & 152 & & 123 & & 43,7 \\
\hline 1965 & 37,4 & 45 & 38,3 & 40 & 37,8 \\
\hline 1966 & 40,4 & 40,8 & 27,2 & 28,9 & 27,9 \\
\hline 1967 & 30,9 & 30,2 & 19,5 & 21,1 & 28,9 \\
\hline 1968 & 33,7 & 31,5 & 24,3 & 21 & 24,7 \\
\hline 1969 & 23,9 & 26,3 & 19,5 & 19,9 & 21,1 \\
\hline 1970 & 22,7 & 20,6 & 24 & 22,4 & 19,8 \\
\hline 1971 & 20,1 & 20,9 & 17,7 & 16,4 & 17,3 \\
\hline 1972 & 15,3 & 17,7 & 16,3 & 16,2 & 14,1 \\
\hline 1973 & 15,6 & 14,8 & 11,2 & 12,1 & 15,9 \\
\hline 1974 & 15,9 & 17,0 & 12,0 & 12,7 & 1,5 \\
\hline 1975 & 13,1 & 14,4 & 11,4 & 12,2 & \\
\hline 1976 & 11,8 & & 9,4 & & \\
\hline 1977 & 10,8 & & 8,6 & & \\
\hline & & & & & \\
\hline
\end{tabular}

INTERPRETAÇÃO DOS RESULTADOS A localização dos pontos, cujas concentraç̃̃es de trítio constam da Tab. 4, encontra-se no mapa da Fig. 1. Observa-se uma distribuição irregular das concentraçōes de trítio confirmando que cada poço é representativo da recarga local em uma área mais ou menos pequena e que a água não se mistura bem dentro do aquífero.

No entanto, mesmo com essa distribuição irregular de concentrações de trítio, é possível diferenciar no aquífero quatro zonas com diferentes concentraçðes médias. Os limites dessas zonas estão indicados no mapa da Fig. 5 assim como os valores da concentração média, número de poços de cada zona, o desvio médio da concentração e o tempo de renovação. Logicamente, os limites dessas zonas não podem ter uma definição precisa. Dentro da zona 2, não se têm dados de concentração de trítio e, portanto, deve ser considerada como uma zona desconhecida a esse respeito.

Podem-se utilizar os valores da concentração de trítio, junto com os correspondentes aos isótopos estáveis, para identificar a relação existente entre poços próximos. Por exemplo, observa-se que os poços IT-401, IT-511, IT-513, IT-514 e, possivelmente, o IT-512 podem estar alimentados da mesma água. Por outro lado, poços tão próximos como os MA-400 e MA-151 têm água diferente, o que é a mesma conclusão obtida a partir dos isótopos estáveis. 


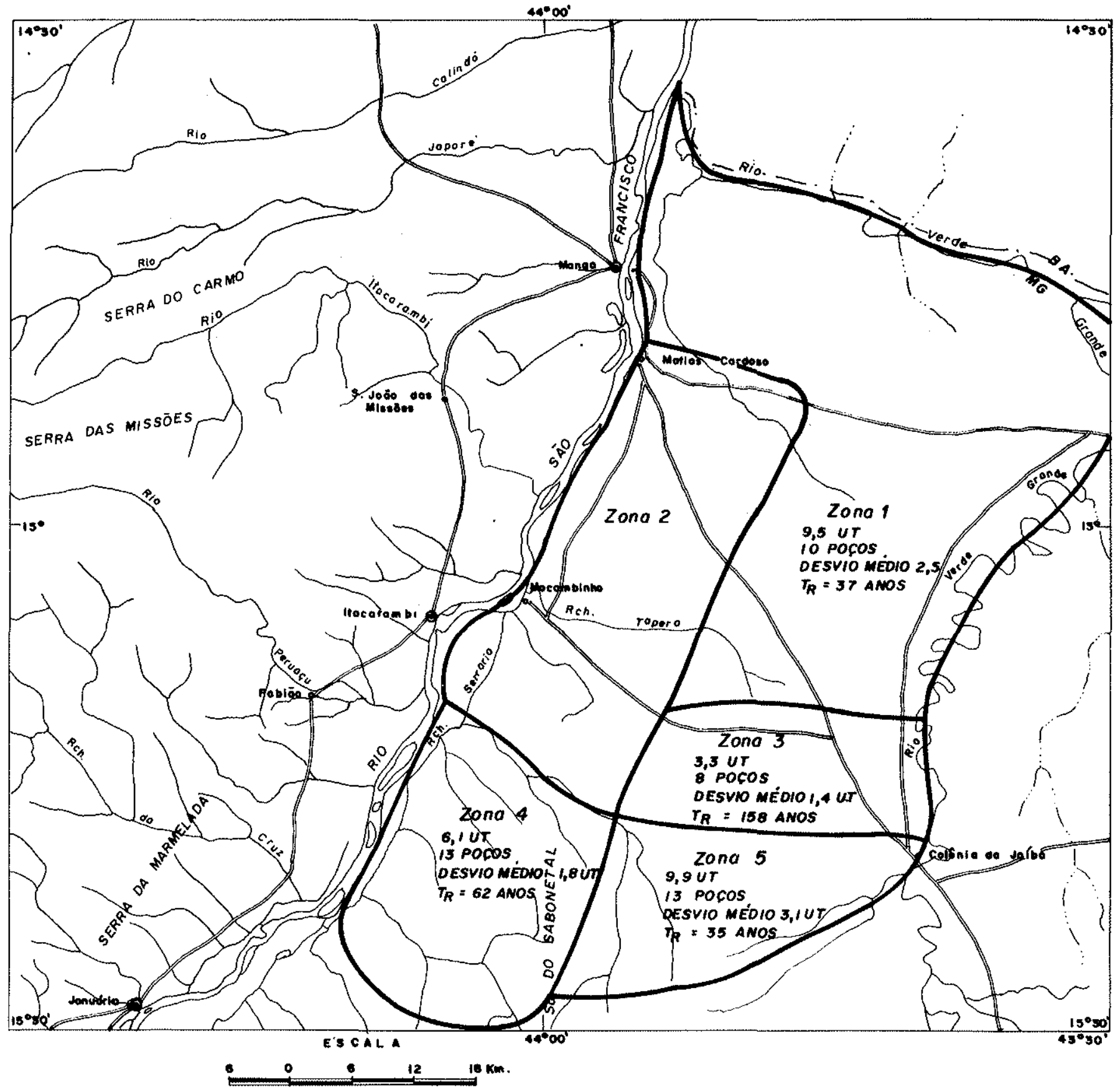

LEGENOA

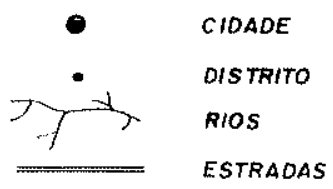

-.- - LIMITE OE ESTADO

ZONas de concentrafōes de trítio

Figura 5 - Definição de zonas a partir das concentrações de trítio 
Relação com outros parâmetros a) Profundidade das fendas. Em treze poços onde foi analisado o trítio, foi também realizada uma perfilagem isotópica com bromo 82 (Nota Técnica TRRS-07/78, CETEC). Tais perfilagens permitem conhecer com boa precisão a profundidade da qual procede a água coletada em cada poço. Dessa forma é possível relacionar essa profundidade à concentração de trítio. Os resultados obtidos encontram-se na Tab. 5. Em linhas gerais, observa-se que a concentração de trítio diminui quando aumenta a profundidade do trecho fendilhado que fornece a água. Como a concentração de trítio está relacionada à idade média da água e, em muitos aquíferos livres, a idade aumenta logaritmicamente com a profundidade, tentou-se relacionar a concentração com o logaritmo da profundidade. $O$ resultado obtido encontra-se na Fig. 6 . Dos treze pontos existentes, nove ajustam-se à reta que obedece á equação $\mathrm{C}_{t}=-5,52 \mathrm{ln} \cdot h+28,1$. Os quatro pontos restantes desviam-se, mais ou menos, da reta. No entan- to é difícil saber se este resultado é produto da casualidade ou corresponde à realidade. Para esclarecer esse ponto é preciso uma informação mais ampla. Se for aceita a equação anterior, podemos calcular, pela mesma, a profundidade de procedência da água para todos os poços incluídos na Tab. 4. Os resultados obtidos foram agrupados em trechos de $10 \mathrm{~m}$, chegando-se à distribuição mostrada na Fig. 7. Observa-se nesta distribuição a presença de dois picos bem definidos, um situado em torno dos $30 \mathrm{~m}$ e outro em torno dos $62 \mathrm{~m}$. Esta distribuição é semelhante à obtida pelas perfilagens isotópicas. No entanto a distribuição está influenciada pelas profundidades da maioria dos poços perfurados, que oscilam entre 20 a $70 \mathrm{~m}$.

b) Isótopos estáveis da água em 37 poços existem dados de concentração de trítio e de isótopos estáveis da água. Os pontos correspondentes foram representados no diagrama da Fig. 8. Observa-se que, em linhas gerais, as águas mais antigas, isto é, com menor concen-

Tabela 4 - Concentrações de tritio nas amostras coletadas, em unidades de trítio (U.T.)

\begin{tabular}{c|c|c|c|c|c}
\hline Referência & U.T. & Referência & U.T. & Referência & U.T. \\
\hline MA- 01 & $9,1 \pm 0,6$ & MA-203 & $7,9 \pm 0,9$ & IT-501 & $5,1 \pm 0,8$ \\
\hline MA-04 & $7,1 \pm 0,7$ & MA-204 & $2,7 \pm 0,7$ & IT-508 & $7,9 \pm 0,9$ \\
\hline MA-06 & $11,6 \pm 0,8$ & MA-400 & $5,5 \pm 0,9$ & IT-511 & $4,5 \pm 0,8$ \\
\hline MA-13 & $5,2 \pm 0,5$ & MA-401 & $4,5 \pm 0,8$ & IT-512 & $0,9 \pm 0,6$ \\
\hline MA-15 & $2,3 \pm 0,6$ & MA-420 & $20,8 \pm 0,6$ & IT-512 & $5,8 \pm 0,9$ \\
\hline MA- 79 & $11,9 \pm 0,9$ & MA-425 & $8,4 \pm 0,7$ & IT-513 & $4,5 \pm 0,7$ \\
\hline MA- 81 & $1,5 \pm 0,6$ & MA-427 & $11,7 \pm 0,8$ & IT-514 & $4,5 \pm 0,8$ \\
\hline MA- 83 & $83 \pm 3$ & MA-432 & $11,1 \pm 0,9$ & IT-516 & $13,0 \pm 1,0$ \\
\hline MA-98 & $6,6 \pm 0,8$ & MA-604 & $3,9 \pm 0,6$ & IT-520 & $6,2 \pm 0,8$ \\
\hline MA-99 & $8,3 \pm 0,6$ & MA-608 & $8,5 \pm 0,7$ & JN-21 & $3,8 \pm 0,8$ \\
\hline MA-106 & $4,9 \pm 0,6$ & MA-614 & $5,2 \pm 0,6$ & JN-401 & $0,5 \pm 0,5$ \\
\hline MA-130 & $4,8 \pm 0,6$ & MA-617 & $1,8 \pm 0,5$ & JN-403 & $12,6 \pm 1,0$ \\
\hline MA-131 & $6,0 \pm 0,8$ & MA-618 & $2,4 \pm 0,7$ & JN-404 & $5,7 \pm 0,7$ \\
\hline MA-134 & $11,2 \pm 0,9$ & MA-623 & $1,3 \pm 0,7$ & M-1 & $4,7 \pm 0,8$ \\
\hline MA-145 & $13,9 \pm 0,8$ & MA-625 & $12,2 \pm 0,9$ & M-2 & $7,5 \pm 0,9$ \\
\hline MA-151 & $10,4 \pm 0,8$ & MA-631 & $7,8 \pm 0,8$ & M-3 & $7,2 \pm 0,8$ \\
\hline MA-195 & $13,3 \pm 1,0$ & MZ-107 & $2,1 \pm 0,7$ & M-4 & $9,4 \pm 0,7$ \\
\hline MA-202 & $12,9 \pm 0,8$ & IT-501 & $0,5 \pm 0,5$ & & - \\
\hline
\end{tabular}


Tabela 5 - Relação entre concentração de trítio e profundidade da qual recebe a água

\begin{tabular}{c|c|c}
\hline Poço & Profundidade $(\mathrm{m})$ & Trítio (U.T.) \\
\hline MA- 79 & 39 & 11,9 \\
\hline MA-131 & 52 & 6,0 \\
\hline MA-145 & 85 & 13,9 \\
\hline MA-151 & 25 & 10,4 \\
\hline MA-400 & 55 & 5,5 \\
\hline MA-427 & 25 & 11,7 \\
\hline MA-604 & 82 & 3,9 \\
\hline MA-608 & 35 & 8,5 \\
\hline MA-614 & 57 & 5,2 \\
\hline MA-617 & 50 & 1,8 \\
\hline MA-618 & 137 & 2,4 \\
\hline MZ-107 & 105 & 2,1 \\
\hline JN-403 & 10 & 12,6 \\
\hline
\end{tabular}

tração de trítio, têm uma concentração menor de oxigênio 18 . Isso poderia estar relacionado com a interpretação dada anteriormente para as diferenças de valores de $\delta_{D}$ e $\delta_{18}$ no aquífero. Nas zonas de maior densidade de poços, a recarga do aquífero está acentuada devido ao rebaixamento dos níveis piezométricos. Como a maior parte dos poços foi perfurada nos últimos anos, não é de se estranhar que nas zonas de maior densidade de poços existam águas mais modernas.

Concentraçao no rio Verde Grande As amostras M-1 até M-4 da Tab. 4 correspondem às águas do rio Verde Grande. A amostra M-1 foi coletada da colônia da Jaíba, as amostras M-2 e M-3 em Gado Bravo e a M-4 perto da desembocadura do rio São Francisco (Fig. 1). As amostras M-2 e M-3 dão um valor médio de 7,35 U.T.

Os resultados indicam que o rio Verde Grande aumenta a quantidade de trítio em seu percurso. No trecho entre colônia da Jaíba e Gado Bravo não existem fluxos superficiais que desembocam no rio. Portanto neste trecho o aumento de trítio só pode ser justificado pelos aportes de águas subterrâneas. A existência desses aportes foi também demonstrada pelos isótopos estáveis da água. Sendo $Q_{1}$ a vazão do rio na colônia da Jaíba; $Q_{2}$, a vazão em Gado Bravo; $q$, a vazão total dos aportes subterrâneos; e $C_{1}, C_{2}$ e $c$ as concentraçðes respectivas de trítio, deverá cumprir-se:

$$
\begin{aligned}
Q_{2} & =Q_{1}+q \\
C_{2} Q_{2} & =C_{1} Q_{1}+c q
\end{aligned}
$$

substituindo $Q_{2}$ na segunda equação, obtém-se:

$$
\frac{q}{Q_{1}}=\frac{C_{2}-C_{1}}{c-C_{2}}
$$

Os valores de $C_{1}$ e $C_{2}$ são os indicados na Tab. 4, isto é, $C_{1}=4,7 \pm 0,8$ U.T. e $C_{2}=7,35 \pm 0,6$ U.T. Para calcular o valor da relação $q / Q_{1}$, tem-se dificuldade de encontrar um valor adequado para $c$, que representa a média ponderada dos aportes de águas subterrâneas. De acordo com a Fig. 5, pode-se considerar um valor de $c$ dado pela expressão:

$$
c=\frac{c_{1} \ell_{1}+c_{3} \ell_{3}+c_{5} \ell_{5}}{\ell_{1} \ell_{3} \ell_{5}}
$$

em que $c_{1}, c_{3}$ e $c_{5}$ são as concentrações de trítio nas zonas 1,3 e 5 e $\ell_{1}, l_{3}$ e $\ell_{5}$ são os comprimentos dos trechos do rio correspondentes a tais zonas. No entanto, esse cálculo não é preciso porque o rio recebe aportes de águas pelas duas margens e não sabemos quais são as concentraçð̃es de trítio na margem direita.

$\mathrm{O}$ valor de $c$ obtido pela Eq. (4) é igual a 8,2 U.T. Com esse valor, a relaçao $q / Q_{1}$ seria igual a 3,1 que parece muito elevado. Resultado mais provável é que o rio Verde Grande receba águas procedentes só de fendas superficiais com elevado conteúdo de trítio. Considerando para $c$ um valor de 11 U.T., representativo desse tipo de fendas (Fig. 6), obtém-se para $q / Q_{1}$ um valor igual a 0,72 que deve estar mais próximo da realidade. Este valor é semelhante ao valor estimado com o deutério. 


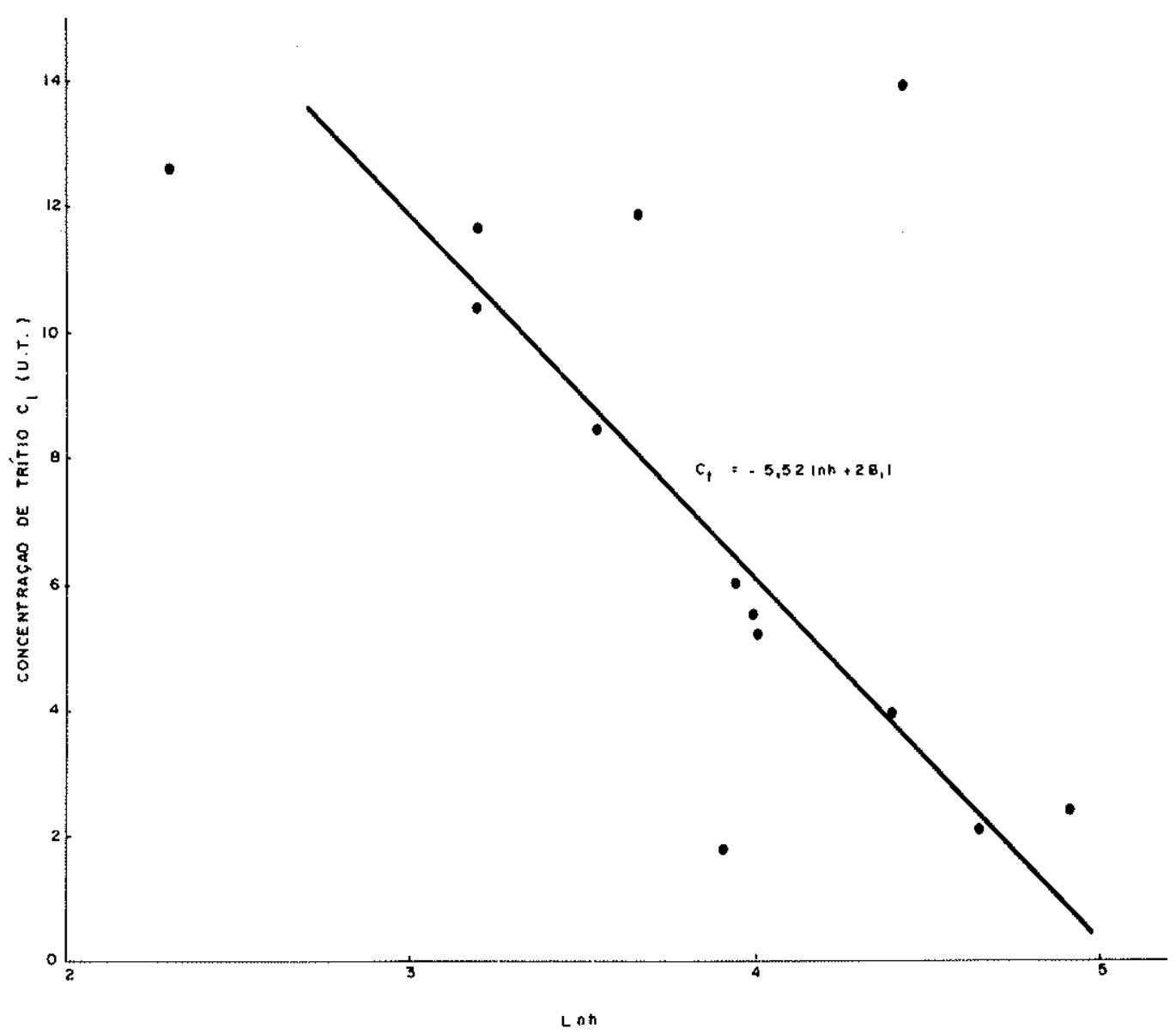

Figura 6 - Relação entre a concentração de tritio e a profundidade $(h)$ da qual procede a água

O valor de $Q_{1}$ para a época da coleta das amostras foi de aproximadamente $4 \mathrm{~m}^{3} / \mathrm{s}$, portanto o valor do aporte subterrâneo no trecho entre a colônia da Jaíba e Gado Bravo $(q)$ seria $2,9 \mathrm{~m}^{3} / \mathrm{s}$.

No trecho compreendido entre Gado Bravo e a desembocadura do rio Verde Grande, a interpretação dos resultados é mais difícil devido à presença do rio Verde Pequeno do qual não se dispõem de dados sobre a concentração de trítio nem sobre a vazão. No entanto observa-se que a concentração de trítio experimenta um novo aumento pelo qual se pode supor que o rio receba mais descarga do aquífero.

Tempo de renovação da água a) Modelo de recarga. $\mathrm{Pa-}$ ra a interpretação das concentrações de trítio em aquíferos cársticos é muito utilizado um modelo de renovação da água de tipo exponencial, também chamado de boa mistura. Trata-se de um modelo interpretativo que supõe o aquífero em equilíbrio, isto é, com recarga igual à descarga. A recarga anual média mantém-se constante e o tempo de mistura de cada fração de recarga é pequeno comparado com o tempo de renovação da água. $\mathrm{Pa}$ ra que este modelo possa ser utilizado, não é preciso que cada fração de recarga deva misturar-se com toda a água existente no aquífero. É suficiente que exista uma boa mistura só numa pequena zona do aquífero. Neste caso, cada poço é representativo de uma pequena zona do aquífero e o tempo de renovação obtido será válido só para esta zona. Entretanto, tendo-se muitos dados, pode-se chegar a um valor médio representativo da totalidade do sistema.

Supondo-se que o aquífero receba todo ano uma recarga constante $R$, e chamando de $V$ o volume dé água armazenada no aquífero, o tempo de renovação é, por definição, $t_{R}=V / R$. A concentração de trítio na recarga é variável com o tempo, sendo indicada pela função $C_{0}(t)$. Esta é chamada função de entrada e corresponde aos valores da última coluna da Tab. 3. Sendo $C(t)$ a função que determina as variações de concentrações de trítio no aquífero, o balanço desse isótopo pode ser expresso da seguinte forma:

$$
R C_{\mathrm{o}}(t)-R C(t)-\lambda V C(t)=V \frac{d c}{d t}
$$

$$
\text { Entradas - Saídas - Perdas = Acumulação }
$$

O tempo $\lambda V C(t)$ corresponde às perdas por desintegração radiativa do trítio. Como o tempo de renovação $t_{R}$ é definido pela relação $V / R$, a equação do balanço anterior toma a forma: 


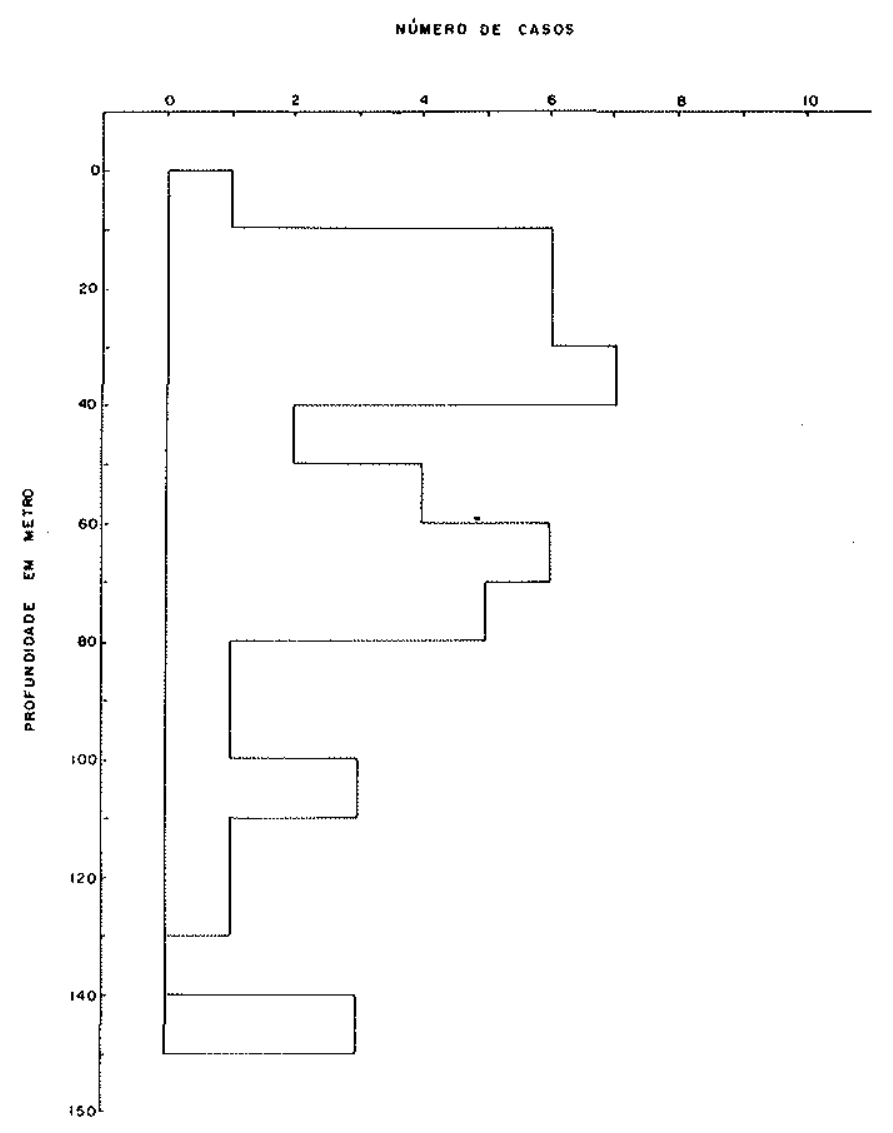

Figura 7 - Distribuição da profundidade de origem da água baseada na concentração de trítio

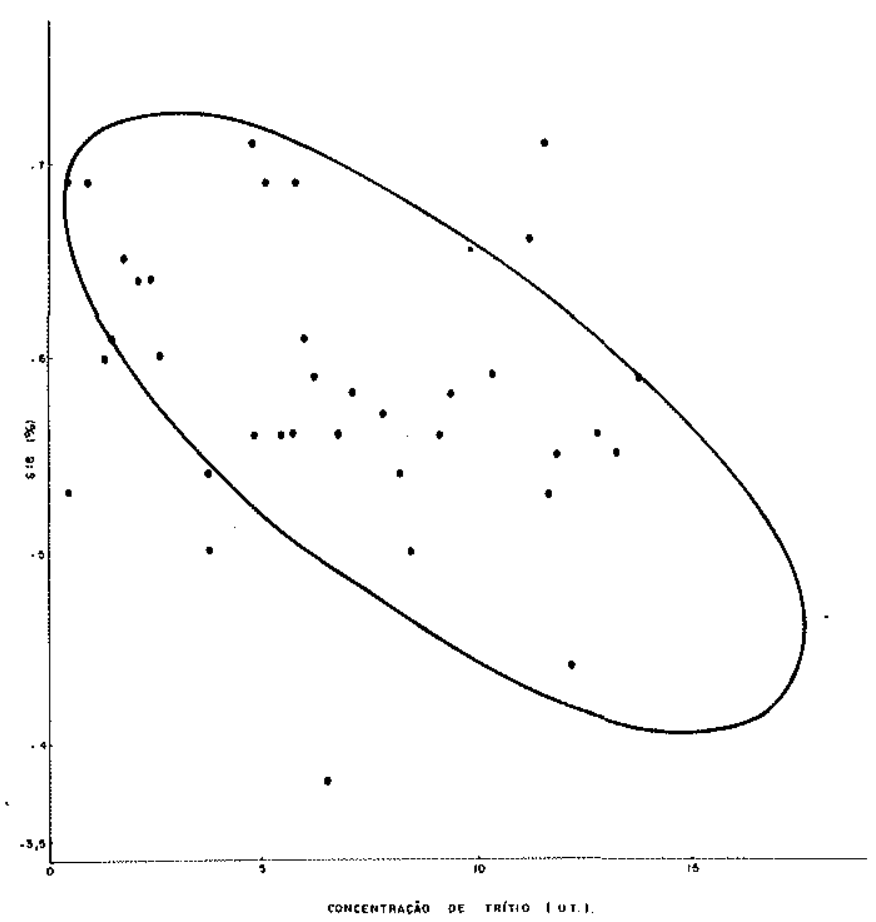

Figura 8 - Relação entre concentração de tritio e o valor de $\delta_{18}$ para água dos poços

$$
\frac{1}{t_{R}}\left[C_{\mathrm{o}}(t)-C(t)\right]-\lambda C(t)=\frac{d c}{d t}
$$

cuja solução é:

$$
C(t)=\frac{1}{t_{R}} \int_{\infty}^{t} C_{\mathrm{o}}(t)^{\prime} \exp .\left[\left(\lambda+\frac{1}{t_{R}}\right)\left(t-t^{\prime}\right)\right] d t(7)
$$

na qual $t$ é o tempo atual e o termo $\left(t-t^{\prime}\right)$, de sinal negativo, representa a idade de cada uma das fraçóes de água que compõem a mistura atual do aquífero.

A forma de utilizar a Eq. (7) é transformá-la num somatório de $n$ termos, sendo $n$ igual ao número de anos transcorridos do início das explosões termonucleares (1952) ao momento atual. Considera-se que a contribuição ao valor atual de $C(t)$ das águas de recarga anteriores a 1952 a 1955 é desprezível comparada à contribuição da recarga dos anos seguintes. Primeiramente, na Eq. (7) prefixa-se um valor determinado de $t_{R}$. Depois calcula-se o valor de $C(t)$ a partir do somatório obtido com todos os valores de $C_{\mathrm{o}}\left(t^{\prime}\right)$ da última coluna da Tab. 3 correspondentes a incrementos negativos do tempo $(t$ $-t^{\prime}$ ). O valor de $\lambda$ é constante e equivale a 0,0565 ano $^{-1}$. Da mesma forma, calculam-se novos valores de $C(t)$ para tempos de renovação diferentes e constrói-se um diagrama. $O$ tempo de renovação para qualquer concentração de trítio obtém-se por leitura direta nesse diagrama.

A relação entre a concentração de trítio $C(t)$ e o tempo de renovação obtida, como foi indicado anteriormente, encontra-se na Fig. 9. Esta curva mostra que o modelo exponencial exige que todas as concentraçőes de trítio no aquífero estejam compreendidas entre 0 e 14,2 U.T. Essa condição é satisfeita de forma aceitável. Só duas amostras tiveram uma concentração maior que 14,2 U.T. Uma dessas amostras (poço MA-83) tem muita possibilidade de ter sido contaminada durante sua análise. A outra é do poço MA-420 com 20,8 U.T.

A forma de curva da Fig. 9 proporciona dois valores do tempo de renovação para uma mesma concentração de trítio, no caso de estar compreendida entre 6,6 e 14,2 U.T. No entanto os valores do tempo de renovação menores que cinco ou dez anos não parecem possíveis, do ponto de vista hidrológico, porque exigiriam uma recarga anual muito elevada ( 80 até $200 \mathrm{~mm} / \mathrm{ano}$ ). Por essa razão, será considerada só a parte descendente da curva. A comprovação de que esse procedimento é correto pode-se realizar repetindo as análises de trítio depois de vários anos. Os novos resultados deverão ser coerentes com os mesmos tempos de renovação.

A reta da Fig. 6 é a relação entre a concentração de trítio e a profundidade da água. Utilizando-se a Fig. 9, as concentrações de trítio podem ser transformadas em tempo de renovação, obtendo-se assim a reta da Fig. 10 que relaciona esse tempo com a profundidade. Excetuando-se três pontos que ficaram muito afastados, os outros dez pontos ajustam-se à reta de equação $t_{R}=$ $1,43 h-17$ ( $t_{R}$ em ano e $h$ em metro).

Para cada valor de concentração de trítio em amostras de água dos poços incluídos na Tab. 4, corresponde um tempo de renovação, segunda a curva da Fig. 9. Obtém-se assim uma série de valores de $t_{R}$ com um valor 


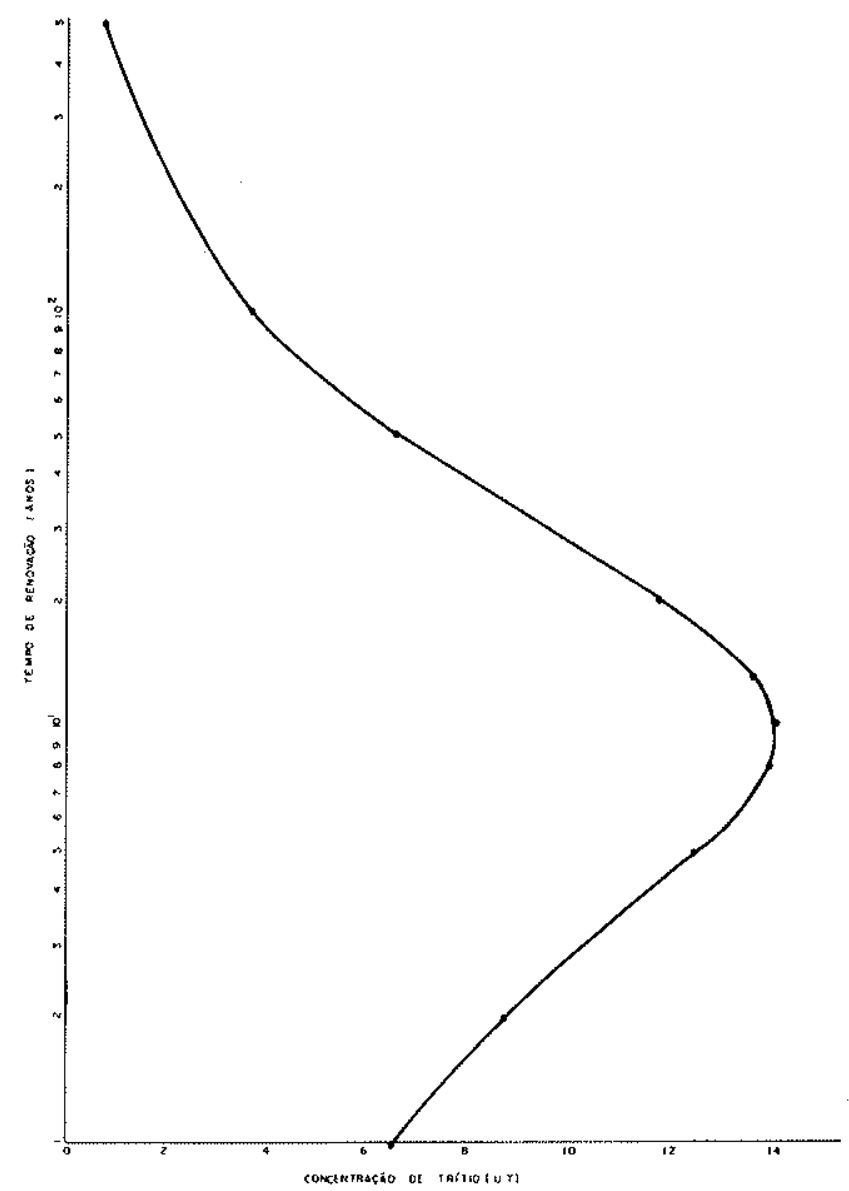

Figura 9- Relação entre concentração de trítio no aquífero e tempo de renovação da água, segundo o modelo exponencial

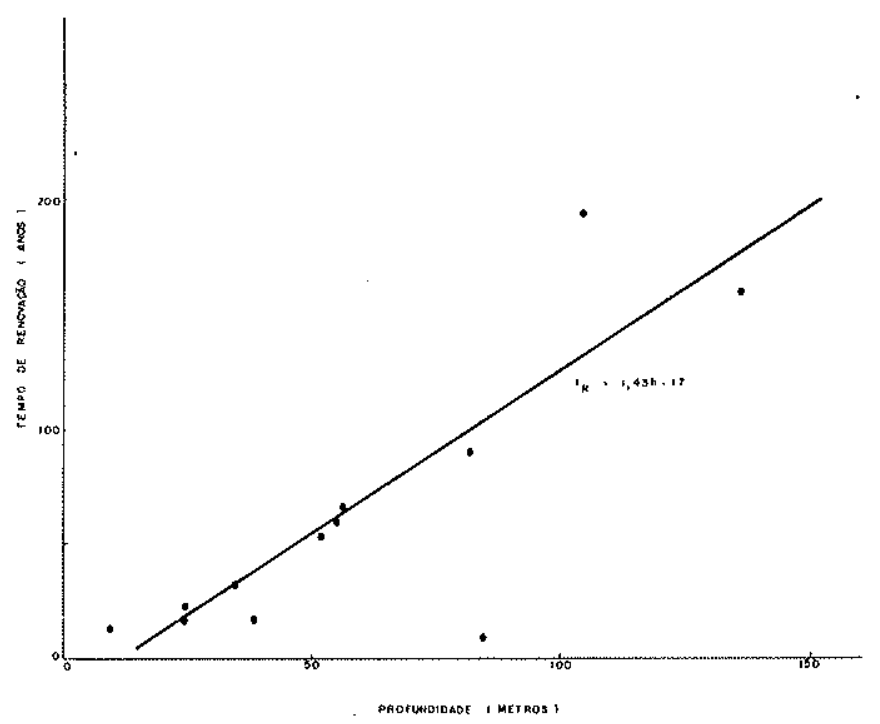

Figura 10 - Relação entre tempo de renovação e profundidade da água médio igual a 101 anos. No entanto, esse valor não pode ser considerado representativo do aquífero, pelas duas razð̃es seguintes:

- A distribuição dos pontos de amostragens é irregular e, portanto, algumas zonas estão mais bem representadas que as outras.

- A relação entre $C(t)$ e $t_{R}$ é do tipo mais ou menos exponencial e basta ter umas poucas amostras com concentrações de trítio muito baixas para aumentar o valor médio de $t_{R}$ de forma considerável. Por exemplo, no caso presente, se eliminarmos no cálculo só cinco amostras que dão um tempo de renovação maior que 200 anos, as amostras restantes darão um valor médio de $t_{R}$ igual a 56,3 anos.

Por essas razőes, considera-se mais representativo dividir a região ocupada pelo aquífero em diferentes zonas, nas quais a concentração de trítio e, portanto, o tempo de renovação sejam, mais ou menos, semelhantes. Uma divisão desse tipo é a indicada na Fig. 5, no qual foram delimitadas quatro zonas diferentes. $\mathrm{O}$ tempo de renovação médio e a superfície aproximada de tais zonas são:

\section{Zona 1}

Tempo de renovação : 37 anos

Superfície $\quad: 1550 \mathrm{~km}^{2}$

Zona 3

Tempo de renovação : 158 anos

Superfície $\quad: 360 \mathrm{~km}^{2}$

Zona 4

Tempo de renovação : 62 anos

Superfície $\quad: 620 \mathrm{~km}^{2}$

Zona 5

Tempo de renovação : 35 anos

Superficie $\quad: 450 \mathrm{~km}^{2}$

De acordo com tais valores, o tempo de renovação médio ponderado para todo o aquífero seria dado por:

$$
t_{R m}=\frac{37 \times 1550+158 \times 360+62 \times 620+35 \times 450}{1550+360+620+450}=56,5 \mathrm{anos}
$$

Por outro Iado, no relatório sobre as perfilagens isotópicas (Nota Técnica TRRS-07/78, CETEC), a espessura média da lâmina de água no aquífero foi estimada em $2 \mathrm{~m}$. Com esse dado e com o tempo de renovação médio anterior, obtém-se uma recarga anual média $R=2000 / 56,5=34,4 \mathrm{~mm} /$ ano. $O$ cálculo pode também ser feito de modo inverso, isto é, a partir da recarga anual média obtida por outro método (por exemplo, balanço de ion cloreto) pode-se determinar a espessura média da lâmina de água.

Convém salientar o elevado tempo de renovação encontrado para a zona 3 . Esse resultado pode ser interpretado de diferentes maneiras:

- Pode ser uma zona de fendilhamento mais profundo que as outras. De acordo com a Fig. 10, a profundidade média das fendas deveria estar em torno de $120 \mathrm{~m}$.

- Outra hipótese é a de que esta possui maior densidade de fendilhamento, isto é, maior espessura de 
lâmina de água. Por exemplo, no caso de ser válida a recarga anual média de $35 \mathrm{~mm} /$ ano, a espessura da lâmina de água no modelo exponencial deveria ser $h=$ $35 \times 158=5530 \mathrm{~mm}$ ou $5,5 \mathrm{~m}$.

Para comprovar se o modelo exponencial funciona de forma correta no caso presente, seria preciso repetir as mediçðes de trítio depois de um período de quatro ou cinco anos. As novas concentraçð̃es de trítio deverão ser mais baixas, mas o tempo de renovação calculado deveria ser da mesma ordem de grandeza. Neste momento, é possível realizar uma certa comprovação desse modelo a partir de três dados correspondentes a três amostras coletadas em abril de 1977, nos poços MA-04, MA-06 e MA-98, analisadas pelo CDTN de Belo Horizonte (MG) (Campos et al., 1977). As concentraçðes de trítio obtidas naquela época durante trabalho realizado pelo CETEC para a RURALMINAS foram:

Poço MA-04

Abril de $1977:$ 7,7 U.T.

Agosto de $1978: 7,1 \pm$ U.T.

Poço MA-06

Abril de $1977: 13,7$ U.T.

Agosto de $1978: 11,6 \pm 0,8$ U.T.

Poço MA-98

Abril de $1977: 8,6$ U.T.

Agosto de $1978: 6,6 \pm 0,8$ U.T.

Com os valores de 1978 e a curva da Fig. 9, obtém-se os tempos de renovação de 46, 21 e 50 anos, respectiva- mente, para os poços MA-04, MA-06 e MA-98. Por outro lado, foi construído um gráfico semelhante ao da Fig. 9 para o ano de 1977. Neste gráfico foram determinadas quais deveriam ter sido as concentraçð̄es de trítio nas três amostras coletadas nos poços em 1977, obtendo-se os valores 7,$9 ; 13,4 ;$ e 7,5 U.T., respectivamente, para os poços MA-04, MA-06 e MA-98. Nos dois primeiros casos, os valores são quase idênticos e, no terceiro, a diferença encontra-se dentro dos erros estatísticos de suas análises de trítio. Parece, portanto, que o modelo exponencial pode funcionar corretamente no caso presente.

CONCLUSÕES O estudo dos isótopos ambientais do karst da região do Jaíba permitiu a obtenção de informação sobre algumas características do aquífero das quais se destacam: $a$ ) as águas subterrâneas do sistema cárstico procedem de precipitaçðes locais infiltradas diretamente no aquífero; $b$ ) o tempo médio de permanência das águas em superfície é pequeno; $c$ ) a concentração de trítio diminui com o aumento da profundidade da água no aquífero; e $d$ ) o tempo médio de renovação da água no aquifero é de aproximadamente 56,5 anos.

Para ratificar essas conclusסes e para se obter outras informaçðes sobre esse aquífero, é aconselhável a coleta de um maior número de amostras de água no aquífero, em épocas de chuvas e de estiagem, por um período superior a dois anos.

\section{BIBLIOGRAFIA}

CAMPOS, M. M.; SALATTI, E.; e MATSUI; E. - 1977 - Utilizaçăo dos teores de Oxigênio-18, D e T como traçadores em estudos hidrogeológicos, RURALMINAS, CETEC, Projeto Planoroeste II, Relatório III-4-a, Belo Horizonte.

CETEC - 1978 - Nota Técnica TRRS-07/78. Projeto "Karst", Belo Horizonte.

CUSTÓDIO, E. e LLAMAS, M. R. - 1975 - Hidrologia subterrânea. Tomo II. Ediciones Omega S.A., Barcelona, pp. 1278-80.

ENVIRONMENTAL ISOTOPE DATA N: $1-1969-$ World survey of isoto pe concentration in precipitation (1953-1963), Technical Reports Series n? 96, International Atomic Energy Agency, Viena.

ENVIRONMENTAL ISOTOPE DATA N. 2-1970 - World survey of isotope concentration in precipitation (1964-1965), Technical Reports Series $n^{\circ}$ 117, International Atomic Energy Agency, Viena.

ENVIRONMENTAL ISOTOPE DATA № 3-1971 - World survey of isotope concentration in precipitation (1966-1967), Technical Reports Series n 129, International Atomic Energy Agency, Viena.
ENVIRONMENTAL ISOTOPE DATA No 4-1973 - World survey of isotope concentration in precipitation (1968-1969), Technical Reports Series $n^{\circ}$ 147, International Atomic Energy Agency, Viena.

ENVIRONMENTAL ISOTOPE DATA № $5-1975$ - World survey of isotope concentration in precipitation (1970-1971), Technical Reports Series $n$ ? 165, International Atomic Energy Agency, Viena.

ENVIRONMENTAL ISOTOPE DATA N: 6 - 1979, World survey of isotope concentration in precipitation (1972-1975), Technical Reports Series n' 192 International Atomic Energy Agency, Viena.

SIEGENTHALER, U. et al. - 1970 - Tritium and oxigen-18 in natural water sample from Switzerland. Isotope Hydrology, International Atomic Energy Agency, Proc. Symp. Vienna, pp. 373-385.

YURTSERVAR, Y. e PAYNE, B. R. - 1978 - Aplication of environmental isotope to groundwater investigations in Qatar, International Symposium on Isotope Hidrology, Nürnberg. Germany Fed. Rep., Paper IAEASM-228/24, june.

Recebido em 26 de novembro de 1980. 